Instrumental A chievements

\title{
Crystal Structure of 2,3-Diaza-1,3-diphenylpropene
}

\author{
Bilal GüNEŞ, ${ }^{* \dagger}$ Süheyla ÖZbey, ${ }^{* *}$ and Habibe TEZCAN*** \\ * Gazi University, Gazi Education Faculty, Physics Education Department, 06500 Beşevler Ankara, Turkey \\ **Hacettepe University, Physics Engineering Department, 06532 Beytepe Ankara, Turkey \\ ***Gazi University, Gazi Education Faculty, Chemistry Education Department, 06500 Beşevler Ankara, Turkey
}

\begin{abstract}
The title compound crystallizes in monoclinic space group $P 2_{1} / c$. There are two molecules in the asymmetric unit. While one of these molecules is in a general position, the other is in disordered position. The angle between the directions of the molecules in the asymmetric unit is $87.5(1)^{\circ}$.
\end{abstract}

(Received May 20, 2002; Accepted November 6, 2002)

The hydrazines and related compounds have been the subject of extensive study because of their chemical properties and biological activities. ${ }^{1}$ As a part of a series of structural investigations of a compound class containing the phenylhydrazine moiety, the title compound was synthesized by the treatment of benzaldehyde with phenylhydrazine. The resultant orange needle-shaped crystals were recrystallized in an ethanol solution. The crystal data were collected on an EnrafNonius CAD-4 diffractometer. Data collection and cell refinement were performed using Enraf-Nonius CAD-4 software. ${ }^{2}$ MolEN ${ }^{3}$ was used for data reduction. The structure was solved by direct methods using SHELXS97. ${ }^{4}$ A refinement was carried out by full-matrix least-squares methods using SHELXL97.5 The disordered atoms (N27, N28 and C29) were assigned to have a site occupation factor of 0.5. Hydrogen atoms, except for $\mathrm{H} 27$ and $\mathrm{H} 29$, which are bonded to disordered atoms, were located from difference Fourier maps and refined isotropically. The H27 and H29 atoms were placed geometrically and refined by the riding method. Molecular graphics were prepared using ORTEPII. ${ }^{6}$ Figure 1 shows a chemical diagram of the title compound. The obtained crystal data and experimental details are given in Table 1 . The final atomic coordinates and equivalent isotropic thermal parameters for non-hydrogen atoms are listed in Table 2. The interatomic distances and angles are presented in Table 3.

The crystal structure of the title compound contains two

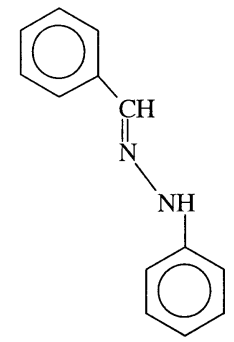

Fig. 1 Chemical structure of the title compound.

† To whom correspondence should be addressed.

E-mail: bgunes@gazi.edu.tr molecules in an asymmetric unit, as shown in Fig. 2. One is an ordered molecule (A) in a general position; the other (B) is a disordered molecule placed with regard to a crystallographic center of symmetry. The angle between the directions of the ordered and disordered molecule in the asymmetric unit is $87.5(1)^{\circ}$. In A the angle between the two benzene rings is $8.8(2)^{\circ}$; these rings are parallel in the disordered molecule B due to crystallographic symmetry. In the crystal, the following intermolecular contacts were observed: C11 ‥N28i; 3.361(8) and $\mathrm{C} 26 \cdots \mathrm{N} 28^{\mathrm{ii}} ; 2.72(1)$, for these contacts the $\mathrm{C}-\mathrm{H} \cdots \mathrm{N}$ angles are $134.6(9)^{\circ}$ and $104.1(9)^{\circ}$, respectively [symmetry codes: (i) $-1+x, 1 / 2-y,-1 / 2+z$, (ii) $1-x,-y, 1-z]$. The above interactions can not be regarded as hydrogen bonding, since the bond length is very long in the first interaction and the concerned angle is

Table 1 Crystal and experimental data

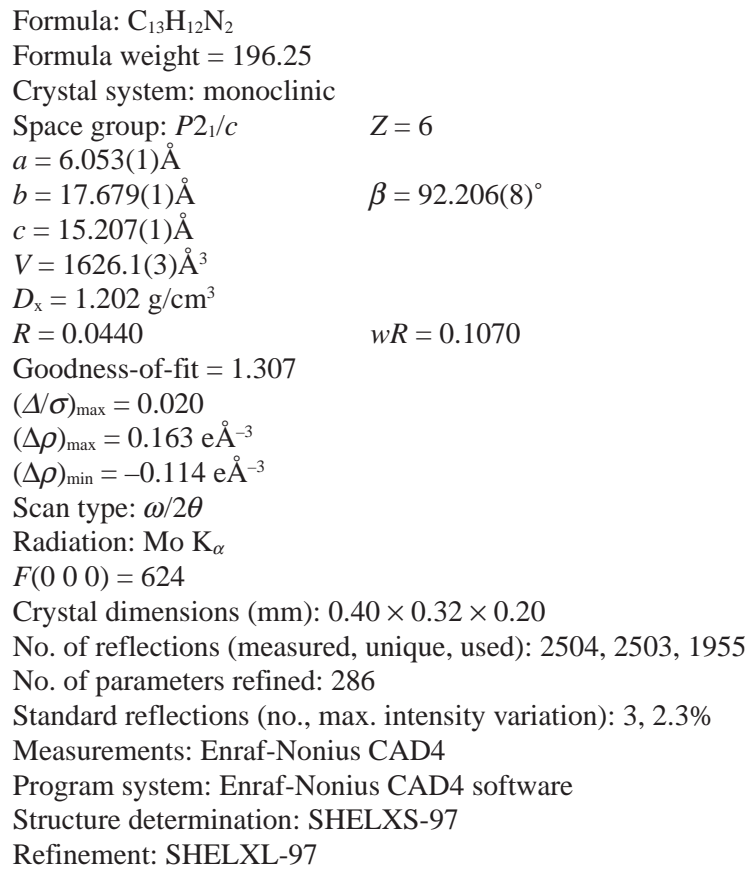


Table 2 Final coordinates and equivalent isotropic displacement parameters of the non-hydrogen atoms

\begin{tabular}{cccccc}
\hline Atom & $x$ & $y$ & $z$ & $U_{\text {eq }}\left[\AA^{2}\right]$ & Occ. \\
\hline N7 & $0.0785(6)$ & $0.2637(2)$ & $0.0646(3)$ & $0.104(2)$ & \\
N8 & $0.0647(5)$ & $0.3099(2)$ & $0.1328(2)$ & $0.0885(9)$ & \\
C1 & $0.2614(6)$ & $0.2145(2)$ & $0.0554(2)$ & $0.084(1)$ & \\
C2 & $0.2663(8)$ & $0.1681(2)$ & $-0.0172(3)$ & $0.092(1)$ & \\
C3 & $0.4450(8)$ & $0.1223(3)$ & $-0.0304(3)$ & $0.102(1)$ & \\
C4 & $0.6197(8)$ & $0.1200(3)$ & $0.0301(3)$ & $0.102(1)$ & \\
C5 & $0.6145(8)$ & $0.1639(3)$ & $0.1036(3)$ & $0.101(1)$ & \\
C6 & $0.4388(7)$ & $0.2111(3)$ & $0.1172(3)$ & $0.094(1)$ & \\
C9 & $-0.1149(8)$ & $0.3497(2)$ & $0.1384(3)$ & $0.085(1)$ & \\
C10 & $-0.1461(6)$ & $0.4031(2)$ & $0.2057(2)$ & $0.081(1)$ & \\
C11 & $-0.3461(7)$ & $0.4417(3)$ & $0.2091(3)$ & $0.097(1)$ & \\
C12 & $-0.3779(8)$ & $0.4962(3)$ & $0.2717(3)$ & $0.103(1)$ & \\
C13 & $-0.2123(8)$ & $0.5129(3)$ & $0.3333(3)$ & $0.102(1)$ & \\
C14 & $-0.0149(8)$ & $0.4738(3)$ & $0.3313(3)$ & $0.100(1)$ & \\
C15 & $0.0185(7)$ & $0.4199(2)$ & $0.2692(3)$ & $0.091(1)$ & \\
& & & & & \\
N27 & $0.743(1)$ & $0.0026(4)$ & $0.4485(5)$ & $0.100(2)$ & 0.5 \\
N28 & $0.4358(9)$ & $0.0192(4)$ & $0.5077(4)$ & $0.086(2)$ & 0.5 \\
C21 & $0.7795(8)$ & $0.0723(3)$ & $0.4118(3)$ & $0.096(1)$ & \\
C22 & $0.9600(8)$ & $0.0947(3)$ & $0.3661(3)$ & $0.106(1)$ & \\
C23 & $0.967(1)$ & $0.1648(4)$ & $0.3291(3)$ & $0.114(2)$ & \\
C24 & $0.795(1)$ & $0.2149(4)$ & $0.3392(3)$ & $0.116(2)$ & \\
C25 & $0.6158(9)$ & $0.1919(3)$ & $0.3862(4)$ & $0.113(1)$ & \\
C26 & $0.6086(8)$ & $0.1214(3)$ & $0.4221(3)$ & $0.098(1)$ & \\
C29 & $0.441(2)$ & $0.0891(7)$ & $0.4806(8)$ & $0.087(3)$ & 0.5 \\
\hline
\end{tabular}

$U_{\mathrm{eq}}=(1 / 3) \sum_{i} \Sigma_{j} U_{i j}\left(a_{i}^{*} a_{j}^{*}\right)\left(\boldsymbol{a}_{i} \cdot \boldsymbol{a}_{j}\right)$.

Table 3 Selected bond distances $(\AA)$ and angles $\left({ }^{\circ}\right)$

\begin{tabular}{|c|c|c|c|c|c|c|c|}
\hline N8 & C9 & \multicolumn{2}{|c|}{$1.300(5)$} & $\mathrm{C} 21$ & N27 & \multicolumn{2}{|c|}{$1.373(9)$} \\
\hline N8 & N7 & \multicolumn{2}{|c|}{$1.325(5)$} & C26 & C29 & \multicolumn{2}{|c|}{$1.489(9)$} \\
\hline N7 & $\mathrm{C} 1$ & \multicolumn{2}{|c|}{$1.419(5)$} & $\mathrm{N} 27$ & N28 & \multicolumn{2}{|c|}{$1.348(9)$} \\
\hline C9 & $\mathrm{C} 10$ & \multicolumn{2}{|c|}{$1.411(6)$} & N28 & C29 & \multicolumn{2}{|c|}{$1.302(9)$} \\
\hline \multirow{2}{*}{$\mathrm{C} 21$} & \multirow[t]{2}{*}{$\mathrm{C} 26$} & \multirow{2}{*}{\multicolumn{2}{|c|}{$1.364(6)$}} & & & & \\
\hline & & & & C26 & $\mathrm{C} 21$ & $\mathrm{~N} 27$ & $112.8(5)$ \\
\hline C9 & N8 & N7 & $117.6(4)$ & C26 & $\mathrm{C} 21$ & $\mathrm{C} 22$ & $119.7(5)$ \\
\hline N8 & N7 & $\mathrm{Cl}$ & $121.9(4)$ & $\mathrm{N} 27$ & $\mathrm{C} 21$ & $\mathrm{C} 22$ & $127.4(5)$ \\
\hline $\mathrm{C} 2$ & $\mathrm{C} 1$ & N7 & $119.1(4)$ & $\mathrm{C} 25$ & C26 & $\mathrm{C} 29$ & $128.6(6)$ \\
\hline C6 & $\mathrm{C} 1$ & N7 & $122.7(4)$ & $\mathrm{C} 21$ & $\mathrm{C} 26$ & C29 & $111.2(6)$ \\
\hline N8 & C9 & $\mathrm{C} 10$ & $123.0(4)$ & N28 & N27 & $\mathrm{C} 21$ & $127.1(6)$ \\
\hline C11 & $\mathrm{C} 10$ & C9 & $119.8(4)$ & C29 & N28 & N27 & $117.3(7)$ \\
\hline C15 & $\mathrm{C} 10$ & C9 & $122.2(4)$ & N28 & C29 & $\mathrm{C} 26$ & $125.3(8)$ \\
\hline
\end{tabular}

very small in the second interaction for hydrogen bonds. ${ }^{6}$ Because the absence of intermolecular hydrogen bonding between these types of molecules causes an unstable structure, the disordered structure is probably caused by the absence of

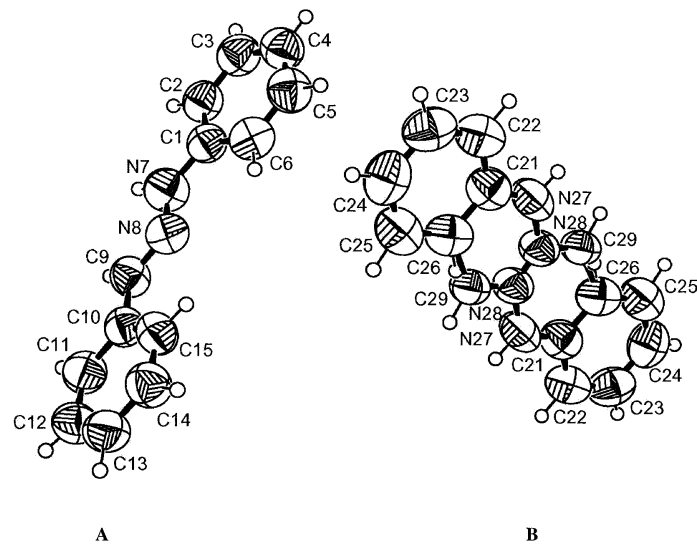

Fig. 2 ORTEP drawing of the asymmetric unit, showing the numbering schemes for atoms at the $50 \%$ probability level. Molecule $\mathrm{B}$ is disordered.

hydrogen bonding between the molecules.

\section{Acknowledgements}

The authors wish to acknowledge the purchase of the CAD4 diffractometer under Grant DPT/TBAG1 of the Scientific and Technical Research Council of Turkey.

\section{References}

1. H. Fun, Z. Lu, C. Duan, Y. Tian, X. You, Y. Guo, and X. Gong, Acta Cryst., 1997, C53, 1452.

2. Enraf-Nonius: CAD-4 Software, 1993, Enraf-Nonius, Delft, The Netherlands.

3. C. K. Fair, MolEN, An Interactive Intelligent System for Crystal Structure Analysis, 1990, Enraf-Nonius, Delft, The Netherlands.

4. G. M. Sheldrick, SHELXS97, Program for the Solution of Crystal Structures, 1997, University of Göttingen, Germany.

5. G. M. Sheldrick, SHELXL97, Program for the Refinement of Crystal Structures, 1997, University of Göttingen, Germany.

6. C. K. Johnson, ORTEP II, Report ORNL-5138, 1976, Oak Ridge National Laboratory, Tennessee, USA. 